\title{
INEFICÁCIA DO ALLOPURINOL EM PACIENTES NA FASE AGUDA DA DOENÇA DE CHAGAS
}

\author{
Liana Lauria-Pires, Cleudson N. de Castro, Antônio \\ Emanuel e Aluizio Prata
}

O allopurinol foi ensaiado no tratamento de seis pacientes internados com fase aguda da doença de Chagas. Todos tinham Trypanosoma cruzi no sangue periférico e área cardíaca normal. A idade variou de 13 a 46 anos e quatro eram do sexo masculino e dois do feminino. $O$ allopurinol foi iniciado após 15 a 20 dias de doença. A medicação foi dada por via oral na dose de 20 a $30 \mathrm{mg} / \mathrm{kg} / \mathrm{dia}$, em duas a quatro tomadas, durante 45 a 60 dias.
A medicação foi bem tolerada e os exames complementares não revelaram alterações, exceto discreta elevação transitória de transaminases em um deles, bloqueio aurículo-ventricular do $19 \mathrm{grau}$ em outro, que posteriormente regrediu. $\mathrm{O}$ xenodiagnóstico e a sorologia não negativaram em nenhum. Posteriormente os pacientes foram tratados com benzonidazol. 